\title{
List of informants
}

I am extremely grateful to the following people for taking part in this investigation. Saya sangat berterima kasih kepada semua orang yang masuk daftar ini atas bantuan anda.

Solo: A.M. Sukardi, Agus Jarwanto, Ambar, Anik Kidayati, Apie Dwi Astuti, Ari Purnomo, Bangun Saputra, Dennis Anton Sulistyo, Desiwulan Sari, Desy Natalia Gunawan, Didit Raditya, Dodik Iswanto, Dwi Maryamah, Dyan Primadyka, Galih Satrio, Hajri Fitri Yanto, Hendro Suyanto, Herlina Prisca Wijaya, Indri Andyani, Jayeng Pranoto, S.P., Joko Purnomo, Jumadi, Koco, Lilik Isyanto, Marwati, Muhammad Isnaeni, Muhammad Ilha Widi Hastuti, Mursamtoro, N.N. Ida Haryani, Nanang Purwanto, Oktaviany Wulansari, Olin Veloni Primanta A., Prasetya Utami, Puspa Suputro, Raden Fajar Rinal Dhani, Rizky Amaliana, Sri Surani Budiasih, Sugiyanto, Wahyu Hernowo, Waluyo, Winarni, Yosep Setiawan, Yudi Tri Laksono.

Makassar: Adithya Perdana, Alfanto, Amelia Ferina, Andi Arfan, Andi Bimawati, Andi Darmawansa, Annas, Arman Djamaluddin, Asma, Asnawing, Audy Sahabuddin Usman, Avriyani Donny, Ayu, Azis B., Baya, Buanawati, Dianti, Saidah Sahdu Handina, Faizah, Farah Dwi Anila, Fatimah, Hajir, Iksan Djamaluddin, Ipa Indrawati, Irdayanti Bangsawan, Iswandi, Judy Tanbungan, Juriah, Khevin Lumentu, Lukman, Merlina, Mia, Muhammad Adam Malik, Muhammad Fadly Syukur, Muhammad Ilham Amin, Muhammad Nasir, Musdalifah, Nisria Nurul Magfirah, Nur Afni, Nur Asmah Mace"q, Nurasiah, Putri Imeld, Rahma Ahmad, Rasnita, Ridwan, Ririn Eka Wulandari, Roby, Rusli, Sakir Rachman, Samsiah, Santi Nurul, Sugianto, Sujana, Sunjaya, Syhruddin Kadr, Teguh Suryadi Slamet, Trisulista, Try Aprili Andi Amier, Wana, Wawah Yudi, Yasriani, Zaenal, Zilfthanah Arranury.

Manado: Dwi Mirdawati, Fanny Inkiriwang, Farida Paembonan, Lisa, Maria Magdalena Palit, Melky Walukow, Merry Sampouw, Priccilia Frede Lono Sampouw, Rahmawati Ilyas, Rezza, Siti Maimunah, Stenly Rindo.

Jakarta: Bambang Prasetyo, Haji S.N. Siregar, Sit, Wati. 